WITCH A World Induced Technical Change Hybrid Model Author(s): Valentina Bosetti, Carlo Carraro, Marzio Galeotti, Emanuele Massetti and Massimo Tavoni

Source: The Energy Journal, Vol. 27, Special Issue: Hybrid Modeling of Energy-Environment Policies: Reconciling Bottom-up and Top-down (2006), pp. 13-37

Published by: International Association for Energy Economics

Stable URL: http://www.jstor.org/stable/23297044

Accessed: 01-12-2015 16:08 UTC

Your use of the JSTOR archive indicates your acceptance of the Terms \& Conditions of Use, available at http://www.jstor.org/page/ info/about/policies/terms.jsp

JSTOR is a not-for-profit service that helps scholars, researchers, and students discover, use, and build upon a wide range of content in a trusted digital archive. We use information technology and tools to increase productivity and facilitate new forms of scholarship. For more information about JSTOR, please contact support@jstor.org. 


\title{
WITCH \\ A World Induced Technical Change Hybrid Model
}

\author{
Valentina Bosetti*, Carlo Carraro†, Marzio Galeotti**, \\ Emanuele Massetti*, Massimo Tavoni*
}

The need for a better understanding of future energy scenarios, of their compatibility with the objective of stabilizing greenhouse gas concentrations, and of their links with climate policy, calls for the development of hybrid models. Hybrid because both the technological detail typical of Bottom Up $(B U)$ models and the long run dynamics typical of Top Down (TD) models are crucially necessary. We present WITCH - World Induced Technical Change Hybrid model - a neoclassical optimal growth model (TD) with energy input detail (BU). The model endogenously accounts for technological progress, both through learning curves affecting prices of new vintages of capital and through $R \& D$ investments. In addition, the model captures the main economic interrelationships between world regions and is designed to analyze the optimal economic and environment policies in each world region as the outcome of a dynamic game. This paper provides a detailed description of the WITCH model, of its Baseline, and of the model calibration procedure.

\section{INTRODUCTION}

Climate change is a long run global phenomenon. Its impacts are felt over a long time horizon, with different adverse geographical and sectoral effects.

The Energy Journal, Hybrid Modeling of Energy-Environment Policies: Reconciling Bottom-up and Top-down. Copyright @2006 by the IAEE. All rights reserved.

* $\quad$ Fondazione Eni Enrico Mattei

$\dagger \quad$ University of Venice and Fondazione Eni Enrico Mattei

** University of Milan and Fondazione Eni Enrico Mattei

This paper is part of the research work being carried out by the Climate Change Modelling and Policy Research Program at the Fondazione Eni Enrico Mattei. Comments and support from Andrea Bigano and Francesco Bosello are gratefully acknowledged. Corresponding author: Valentina Bosetti, Fondazione Eni Enrico Mattei, Corso Magenta 63, Milan, Italy. E-mail: valentina.bosetti@ feem.it.

Paper presented at: SURED 2006, June 4-9, Ascona, Switzerland; International Energy Workshop 2006, June 27-29, Cape Town, South Africa; 3rd World Congress of Environmental and Resource Economists, July 3-7, Kyoto, Japan. 


\section{4 / The Energy Journal}

Climate change negatively affects welfare of present and future generations. It is an uncertain phenomenon and its control is likely to be difficult and costly. Because no one really believes or is ready to accept that the solution to the climate change problem is to reduce the pace of economic growth, policy analyses have often focused on changes in technology that could bring about the long sought de-coupling of economic growth from generation of polluting emissions. It is indeed widely recognized that without drastic technological change, in particular in energy technologies, it will be difficult to control the dynamics of climate change and its impacts on ecosystems and economic systems.

As a consequence, a model to be used for climate policy analysis should be able to capture the dynamics of technical change and the relationships between technical change and the main economic and policy variables. However, this is not an easy task. A model of technology development, adoption and diffusion should also take into account the long run dimension of the climate change problem, the interdependence of the needs of present and future generations, the linkages and externalities between different geographical regions and economic sectors, the dynamics of investments and population, and the uncertainty pervading the climate change phenomenon and its effects. The ideal model would feature all the above aspects and should be computationally manageable. Unfortunately, this ideal model does not yet exist. Existing classes of models stress or describe in detail some but not all the above aspects. Generally speaking, economists pay more attention to the economic dimension of climate change within their top-down (TD) models, whereas system analysts or engineers focus on the technological dimension of the problem in their bottom-up (BU) models

In this paper we present a new model called WITCH (World Induced Technical Change Hybrid) designed to at least partly bridge the gap among model classes. WITCH is a top-down neoclassical optimal growth model with an energy input specification in the spirit of a bottom-up model, meant to analyze optimal climate mitigation strategies within a game-theoretical framework, while portraying with adequate detail the evolution of energy technologies and allowing for endogenous technological progress. It is a "hard link hybrid" model in the sense that the energy sector is contained within the economy: capital and resources for energy generation are therefore allocated optimally with respect to the whole economy. As such, WITCH is in a good position - at least in principle - to appropriately describe the dynamics of the relevant variables of the problem (investments in energy technologies, final good and R\&D, direct consumption of fuels). Finally, the model dynamic and game theoretical features allow us to account for both the time and geographical dimensions of climate change.

The outline of the paper is as follows. In the next section we present the structure of the model and its features. In section 3 we describe the calibration procedure. Section 4 outlines the main results of our Baseline scenario. A few concluding remarks are contained in Section 5. 


\section{MODEL DESCRIPTION}

\subsection{General Features}

WITCH is a Ramsey-type neoclassical optimal growth hybrid model defined for 12 macro regions (Figure 1). For each of them a central planner chooses the optimal paths of the control variables - investments in different capital stocks, in $R \& D$, in energy technologies and consumption of fossil fuels- so as to maximize welfare, defined as the regional present value of log per capita consumption. ${ }^{1}$ WITCH is a truly dynamic model in the sense that at each time step forwardlooking agents maximize welfare simultaneously and strategically with respect to the other decision makers. Therefore, the dynamic profile of optimal investments in different technologies is one of the outcomes of the model. These investment strategies are optimized by taking into account both economic and environmental externalities. The investment profile for each technology is the solution of an

\section{Figure 1. Regions of the WITCH Model}

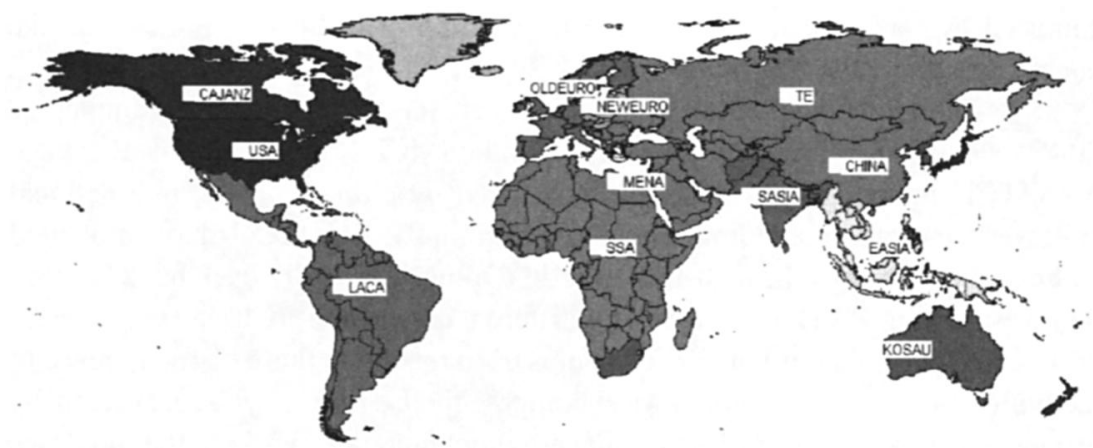

Regions:

1) CAJANZ (Canada, Japan, New Zealand)

2) USA

3) LACA (Latin America, Mexico and Caribbean)

4) OLDEURO (Old Europe)

5) NEWEURO (New Europe)

6) MENA (Middle East and North Africa)

7) SSA (Sub-Saharan Africa excl. South Africa)

8) TE (Transition Economies)

9) SASIA (South Asia)

10) CHINA (including Taiwan)

11) EASIA (South East Asia)

12) KOSAU (Korea, South Africa, and Australia)

1. Population is exogenous in the model. The full list of model equations together with the list of variables can be found in the Appendix. 


\section{6 / The Energy Journal}

inter-temporal game between the 12 regions. More specifically, these 12 regions behave strategically with respect to all decision variables by playing an openloop Nash game. From a top-down perspective this enables us to analyze both the geographical dimension (e.g. rich vs. poor regions) and the time dimension (e.g. present vs. future generations) of climate policy. All regions determine their optimal strategies by maximizing social welfare, with climate damages taken into account through a feedback from an integrated climate module.

Optimization growth models are usually very limited in terms of technological detail. This severely constraints the analysis of climate change issues, which are closely related to the evolution of energy sector technologies. In WITCH this sector is considerably richer than that of macro-growth models. It separates electric and non-electric uses of energy, features seven power generation technologies and includes the use of multiple fuels: oil, natural gas, coal, uranium, traditional biomass and biofuels. This kind of detail in the energy sector - although still much simpler than that of large scale energy system models - is to our knowledge a novelty for this class of models and enables us to reasonably portray future energy and technological scenarios and to assess their compatibility with the goal of stabilizing greenhouse gases concentrations. Also, by endogenously modelling fuel prices, as well as the cost of storing the $\mathrm{CO}_{2}$ captured, we are able to evaluate the implication of mitigation policies on the energy system in all its components.

Following the recent research in climate modelling (see, for example, the 2006 special issue of the Energy Journal on the IMCP Project), technical change in WITCH is endogenous and can be induced by climate policy, international spillovers and other economic effects. Traditionally, BU models have modelled technological change through Learning-by-Doing, while TD ones have focused on investment in R\&D, often reaching different conclusions (Clarke and Weyant, 2002). The hybrid nature of WITCH helps us to reconcile these distinct views. In the bottom up part of the model we encompass the Learning-by-Doing effects by bringing in experience curves for all energy technologies, while in the top down part we account for the accumulation of knowledge (via R\&D) and for its effects on energy efficiency and the cost of advanced biofuels.

In comparison to other optimal growth models, WITCH shares a game set-up similar to that in RICE (Nordhaus and Boyer, 2000), but departs from the stylized representation of the energy sector by featuring richer technological detail, technical change, natural resource depletion etc.. MERGE (Manne, Mendelsohn and Richels, 1995) links a simple top-down model to a bottom-up part that returns the cost of energy; in contrast, WITCH is a single model that represents the energy sector within the economy, and therefore chooses the energy technology investment paths coherently with the optimal growth structure. Also, WITCH features a non-cooperative game among the regions. With respect to MIND (Edenhofer, Bauer and Kriegler, 2005) - an optimal growth model with an energy detail - WITCH possesses richer technological detail, differentiates the electric and non-electric energy uses and is a regional model. 
The model is solved numerically in GAMS/CONOPT for 30 5-year periods, although only 20 are retained as we do not impose terminal conditions. Solution time for the Baseline scenario is approximately 30 minutes on a standard Pentium PC. The code is available from the authors upon request.

\subsection{The Model Structure}

Output is produced by aggregating factors via nested Constant Elasticity of Substitution (CES) functions as shown in Figure 2. Elasticities of substitution are also reported. In particular, final good production of region $n$ at time $t$ is obtained by combining a Cobb-Douglas bundle of capital accumulated for final good production $K_{C}$ and labour $L$ with energy services $E S$ in the following way:

$$
Y(n, t)=\frac{\operatorname{TFP}(n, t)\left[a(n)\left(K_{C}^{1-\beta(n)}(n, t) L^{\beta(n)}(n, t)\right)^{\rho}+(1-a(n)) E S(n, t)^{\rho}\right]^{1 / \rho}}{\Omega(n, t)}
$$

where TFP represents total factor productivity which evolves exogenously over time and $\Omega$ is the damage that accounts for the feedback of temperature rise on production. Consumption of the single final good $C$ is obtained via the economy budget constraint:

$$
\begin{aligned}
C(n, t)= & Y(n, t)-I_{C}(n, t)-\Sigma_{j} I_{R \& D_{j}}(n, t)-\Sigma_{j} I_{j}(n, t)-\Sigma_{j} O \& M_{j}(n, t) \\
& -\Sigma_{f}\left(P_{f}(n, t) X_{f, e x t r}(n, t)+P_{f}^{i n t}(t) X_{f, n e t i m p}(n, t)\right) \\
& -P_{C C S}(n, t) C C S(n, t)
\end{aligned}
$$

i.e., from output $Y$ we subtract investment in final good - labelled by $I_{C}$-in energy R\&Ds and in each energy technology - labelled by $j$ - as well as expenditure for Operation and Maintenance, denoted with $O \& M$. Expenditure on fuels - labelled by $f$-enter either as extraction costs, $X_{f, e x t r}$ or as net imports, $X_{\text {fimp }}$. In particular if a country is a net oil exporter, this latter variable is negative and measures revenues from fuels exports. Finally, the cost of transporting and storing the captured $\mathrm{CO}_{2}$ is deducted. The latter is endogenous and depends on the quantity captured and injected in each region.

Fossil fuels use generates $\mathrm{CO}_{2}$ emissions, computed by applying stoichiometric coefficients to energy use. The quantity of carbon captured with CCS is subtracted from the carbon balance. Emissions are fed into a stylized three-box climate module (the dynamics is described in Nordhaus and Boyer, 2000) which returns the magnitude of temperature increases relative to preindustrial levels. The increase in temperature creates a wedge between output gross and net of climate change effects through the region-specific quadratic damage function $\Omega$. 


\section{Figure 2. The Production Nest and the Elasticities of Substitution}

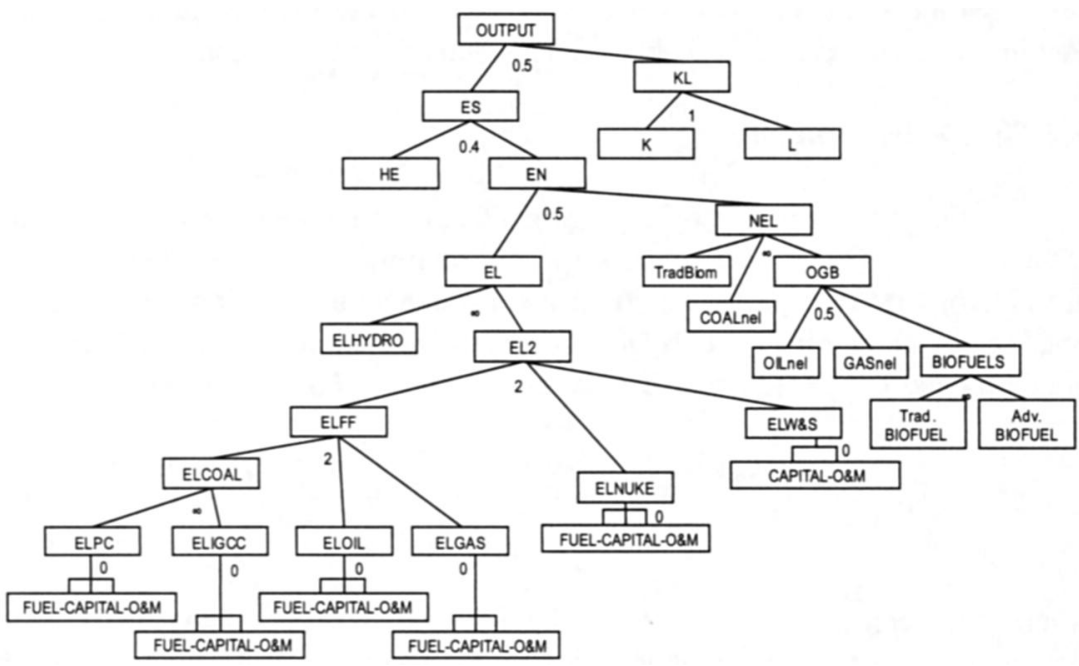

Legenda:

$\mathrm{KL}=$ capital-labour aggregate

$\mathrm{K}=$ capital invested in the production of final good

$\mathrm{L}=$ Labour

$\mathrm{ES}=$ Energy services

$\mathrm{HE}=$ Energy $\mathrm{R} \& \mathrm{D}$ capital

$\mathrm{EN}=$ Energy

$\mathrm{EL}=$ Electric energy use

NEL $=$ Non-electric energy use

OGB $=$ Oil, Gas and Biofuel nest

ELFF $=$ Fossil fuel electricity nest

W\&S $=$ Wind and Solar

$\mathrm{ELj}=$ Electricity generated with the technology $\mathrm{j}$

TradBiom $=$ Traditional Biomass

$\mathrm{Kj}=$ Capital for generation of electricity with technology $\mathrm{j}$

$\mathrm{O} \& \mathrm{Mj}=$ Operation and Maintenance costs for generation of electricity with technology $\mathrm{j}$

'FUELj'el = Fuel use for generation of electricity with technology $j$

'FUELj'nel = Direct fuel use in the non-electric energy use

\subsection{Non-cooperative Solution}

In WITCH strategies taken in one region of the world affect what goes on in all the other regions. This implies that the equilibrium of the model, i.e. the optimal intertemporal investment, R\&D strategies and direct consumption of natural resources, must be computed by solving a dynamic game. Regions interact through five channels.

First, at each time period, the prices of oil, coal, gas and uranium depend on the consumption in the rest of the world. Thus, investment decisions, consumption 
choices and R\&D investment in any country at any time period indirectly affect all other countries' choices. Consider for example the impact of a massive reduction of oil consumption in the USA and in Europe alone, for example stimulated by policies that promote the deployment of biofuels. This would induce a lower world oil price and thus stimulate higher consumption and emissions in the rest of the world. This rebound effect weakens the mitigation effort and acts as a restraint to this kind of unilateral policies. Second, at any time period, emissions of $\mathrm{CO}_{2}$ from each region change the average world temperature and this affects the shadow value of carbon emissions in all other regions. Third, investment decisions in electricity generation technologies in each region at each time period, affect other regions by changing the cumulative world installed capacity which in turn affects investment costs via Learning-by-Doing. A fourth channel of interaction derives from the international R\&D spillovers that affect the costs of advanced biofuels. Finally, a fifth channel is at work if the model is used to analyze the effects of emissions trading. With an active emission permits market regions interact via this channel which equalizes marginal abatement costs across regions, with all the consequences of this result on R\&D effort and investment choices.

WITCH incorporates these five channels of interaction to characterize the interdependency of all countries' climate, energy and technology policies. We model the interactions among world regions as a non-cooperative Nash game, which is solved recursively and yields an Open Loop Nash Equilibrium. The solution algorithm works as follows. At each iteration, the social planner of every region takes as given the behaviour of other players produced by the previous iteration and sets the optimal value of all choice variables; this newly computed level of variables is stored and then fed to the next round of optimizations. The process is iterated until each region's behaviour converges in the sense that each region's choice is the best response to all other regions' best responses to its behaviour. Convergence is rather fast (around fifty iterations) and the uniqueness of the solution has been tested using alternative starting conditions. The way in which the algorithm is constructed makes the solution invariant to different regions orderings.

\subsection{The Energy Sector}

Figure 2 provides a diagrammatic description of the structure of the energy sector in WITCH and identifies the main technologies for the production of electric and non electric energy.

Energy services $E S$, an input of (1), combines energy with a variable, $H E$, that represents technological advances stemming from energy R\&D investment in energy efficiency improvement. As in Popp (2004), an increase in energy $\mathrm{R} \& \mathrm{D}$ efforts improves the efficiency with which energy, $E N$, is translated into energy services, $E S$, e.g. more efficient car engines, trains, technical equipment or light bulbs.

$E N$ is an aggregate of electric, $E L$, and non-electric energy, $N E L$. Contrary to what is specified in other top-down growth models - such as DEMETER 
(Gerlagh and van der Zwaan, 2004) and MIND (Edenhofer, Bauer and Kriegler, 2005) - in WITCH the whole energy demand does not coincide with electricity. We believe this is an important distinction as reducing emissions is traditionally more challenging in the non-electric sector, and its neglect would seriously overestimate the potential GHGs control achievements.

Non-electric energy is obtained by linearly adding coal and traditional biomass on the one hand and an oil-gas-biofuels $(O G B)$ aggregate on the other. The use of coal in non-electric energy production (COALnel) is quite small and limited to a few world regions, and is thus assumed to decrease exogenously over time in the same fashion as traditional biomass (TradBiom). The oil-gas-biofuels aggregate combines oil (OILnel), biofuels (Biofuels) and natural gas (GASnel) sources. In WITCH, ethanol is produced from sugar cane, wheat or corn (Trad Biofuel), or from cellulosic rich biomass (Advanced Biofuel). ${ }^{2}$ The two different qualities of ethanol add up linearly.

As for the electric use of energy, nuclear power (ELNUKE) and renewables in the form of wind turbines and photovoltaic panels $(E L W \& S)$ are combined with fossil fuel-based electricity $(E L F F)$, the output of thermoelectric plants using coal, oil and natural gas (ELCOAL,ELOIL and ELGAS). In this way, we are able to distinguish more interchangeable power generation technologies, such as the fossil-fuelled ones, from the other ones. Coal-based electricity itself is obtained by linear aggregation of traditional pulverized coal technologies (ELPC) and integrated gasification combined cycle with CCS (ELIGCC). Hydroelectric power (ELHYDRO) is added to the total electric composite; because of its constrained deployment due to limited site availability, we assume that it evolves exogenously, in accordance with full resource exploitation.

One might note that by using CES function we aggregate the various forms of energy non linearly. This kind of aggregation is common in economic models, to represent a less than infinite substitutability among factors: moving away from an established energy mix takes place at a higher cost than it would happen in a least cost minimization framework. This is also in agreement with econometric studies on inter-fuel substitution, which find low sensitivities of energy consumption to own and cross energy prices. CES function bundling allows for contemporaneous investments in different technologies which conform with baseyear calibrated factor shares and chosen elasticity of substitution, in contrast to linear aggregation where exogenous constraints on single (or a combination of) technologies are needed to return a portfolio of several investments. Finally, one should keep in mind that in economic models such as WITCH energy itself is an intermediate input, an aggregation of factors of production (capital, resources etc).

For each technology $j$ (wind and solar, hydroelectric, nuclear, traditional coal, IGCC with CCS, oil and gas) at time $t$ and in each region $n$, electricity

2. Cellulosic feedstock comprises agricultural wastes (wheat straw, corn stover, rice straw and bagasse), forest residue (underutilised wood and logging residues, dead wood, excess saplings and small trees), energy crops (fast growing trees, shrubs, grasses such hybrid poplars, willows and switchgrass). For a description of the cellulosic ethanol production see IEA (2004b). 
is obtained by combining three factors in fixed proportions: (i) the installed power generation capacity $(K)$ measured in power capacity units, (ii) operation and maintenance equipment $(O \& M)$ in final good units and (iii) fuel resources consumption $(X)$ expressed in energy units, when needed. The resulting Leontief technology is as follows:

$$
E L_{j}(n, t)=\min \left\{\mu_{n, j} K_{j}(n, t) ; \tau_{n, j} O \& M_{j}(n, t) ; \zeta_{n, j} X_{j, E L}(n, t)\right\}
$$

The parameters governing the production function take into account the technical features of each power production technology. Thus $\mu$ translates power capacity into electricity generation (i.e. from TW to TWh) through a plant utilization rate (hours per year) which allows us to take into consideration the fact that some technologies, noticeably new renewables such as wind and solar power, are penalized by comparatively lower utilization factors; $\tau$ differentiates operation and maintenance costs among technologies, i.e. nuclear power is more expensive to run and maintain than a natural gas combined cycle (NGCC); finally, $\zeta$ measures (the reciprocal of) power plant fuel efficiencies and yields the quantity of fuels needed to produce a KWh of electricity. ELHYDRO and ELW\&S are assumed to have efficiency equal to one, as they do not consume any fuel: the production process thus reduces to a two-factor Leontief production function.

It is important to stress the fact that power generation capacity is not equivalent to cumulated investment in that specific technology, as different plants have different investment costs in terms of final output. That is:

$$
K_{j}(n, t+1)=K_{j}(n, t)\left(1-\delta_{j}\right)+\frac{I_{j}(n, t)}{S C_{j}(n, t)}
$$

where $\delta_{j}$ is the rate of depreciation and $S C_{j}$ is the cost of installing power generation capacity of type $j$, which is time and region-specific. It is worth noting that depreciation rates $\delta_{j}$ are set consistently with the power plants' lifetime, so that again we are able to take into account the technical specifications of each different electricity production technology.

An important feature of WITCH is that the cost of electricity generation is endogenously determined. WITCH calculates the cost of electricity generation as the sum of the cost of capital invested in plants and the expenditures for O\&M and fuels. Since the cost of capital is equal to its marginal product, as capital accumulation proceeds capital-intensive electricity generation technologies, such as nuclear or wind and solar, become more and more preferable to variable cost-intensive ones such as gas. Indeed, whereas at the beginning of the optimization period regions with high interest rates - such as the developing ones - disfavour capital intensive power generation technologies, in the long run the model tends to prefer capital-intensive to fuelintensive electricity production. Note that this feature is not shared by energy 
system models, as they are not able to ensure capital market equilibrium, as noted in Bauer, Edenhofer and Kypreos (2005). Since investment costs, O\&M costs, fuel efficiency for each technology and fuel prices are region-specific, we obtain a high degree of realism in constructing relative prices of different ways of producing electricity in the 12 regions considered. ${ }^{3}$

\subsection{Exhaustible Resources}

Four non renewable fuels are considered in the model - coal, crude oil, natural gas and uranium - whose cost follows a long-term trend that reflects their exhaustibility. We abstract from short-term fluctuations and model the time path of the resource $f$ price starting from a reduced-form cost function that allows for non-linearity in the ratio of cumulative extraction to available resources. ${ }^{4}$ Resources initially in place are region specific and so are extraction cost curves. Thus, for each fuel $f$ we have:

$$
c_{f}(n, t)=q_{f}(n, t)\left(\chi_{f}(n)+\pi_{f}(n)\left[Q_{f}(n, t-1) / \bar{Q}_{f}(n, t)\right]^{\psi} f^{(n)}\right)
$$

where $c$ is the regional cost of resource $f$, depending on current extraction $q_{f}$ as well as on cumulative extraction $Q_{f}$ and on a region-specific markup, $\chi_{f}(n) ; \bar{Q}_{f}$ is the amount of total resources at time $t$ and $\pi_{f}(n)$ measures the relative importance of the depletion effect. ${ }^{5}$ Assuming competitive markets, the regional price $P_{f}(n, t)$ is equal to the marginal cost:

$$
\begin{aligned}
& \left.P_{f}(n, t)=\chi_{f}(n)+\pi_{f}(n)\left[Q_{f}(n, t-1) / \bar{Q}_{f}(n, t)\right]^{\psi_{f}(n)}\right) \\
& Q_{f}(n, t-1)=Q_{f}(n, 0)+\Sigma_{s=0}^{t-1} X_{f, e x t r}(n, s)
\end{aligned}
$$

The second expression represents cumulative extraction and $X_{f, e x t r}$ is the amount of fuel $f$ extracted in region $n$ at time $t$. Fuels are traded among regions at an international market clearing price $P_{f}^{\text {int }}(t)$. Each region can thus opt for autarky or to trade in the market, either as a net buyer or a net seller of fuels: in the former case, the net import of fuels $X_{\text {f, netimp }}$ take on positive values, and negative in the latter. ${ }^{6}$

3. To our knowledge, the endogenous determination of electricity prices is a novelty in optimal growth integrated assessment models.

4. Hansen, Epple and Roberds (1985) use a similar cost function that allows for non-linearity also in the rate of extraction.

5. See Section 3 for more details.

6. The results presented in this paper are obtained using a simplified version of the model where fuel trade is not endogenous, but simply keeps track of exogenously determined traded fuel into the budget constraint. This "accounting" mechanism is more computationally tractable and, at the same time allows us to keep track of welfare effects due to trade in resources. 


\section{$2.5 \mathrm{CO}_{2}$ Emissions}

Since WITCH offers the possibility of tracing consumption of fossil fuels, GHGs emissions that originate from their combustion are derived by applying the corresponding stoichiometric coefficients to total consumption. Even though we presently use a climate module that responds only to $\mathrm{CO}_{2}$ emissions, a multi-gas climate module can easily be incorporated in WITCH thus allowing the introduction of gas-specific emissions ceilings. ${ }^{7}$ For each region $n, \mathrm{CO}_{2}$ emissions from combustion of fossil fuels are derived as follows:

$$
\mathrm{CO}_{2}(n, t)=\Sigma_{f} \omega_{f, \mathrm{CO}_{2}} X_{f}(n, t)-C C S(n, t)
$$

where $\omega_{f, \mathrm{CO}_{2}}$ is the stoichiometric coefficient for $\mathrm{CO}_{2}$ emissions of fuel $f$ and $C C S$ stands for the amount of $\mathrm{CO}_{2}$ captured and sequestered while producing electricity in the coal IGCC power plant. As said above, when analyzing climate policy, regions and/or countries may be allowed to trade their emissions allowances in a global or regional carbon market.

Finally, the climate module of WITCH delivers emissions from land use change that are added to emissions from combustion of fossil fuels to determine atmospheric concentrations as in Nordhaus and Boyer (2000).

\subsection{Endogenous Technical Change}

In WITCH, technical change is endogenous and is driven both by Learning-by-Doing (LbD) effects and by energy R\&D investments. These two factors of technological improvements act through two different channels: LbD is specific to the power generation industry, while R\&D affects the non-electric sector and the overall system energy efficiency.

By incorporating LbD effects in electricity generation, we are able to reproduce the observed empirical relation for which the investment cost of a given technology decreases with accumulation of installed capacity. This representation has proven important in areas such as the renewable energy sector where, for example, the installation costs of wind turbines have steadily declined at a constant rate. Learning rates depend on a variety of factors - not least of public nature - and vary considerably across countries. In our framework we use world learning curves, where investment costs decline with the world installed capacity. In other words, we assume perfect technology spillovers and constant learning rates across countries, which is reasonable considering that any time step in the model corresponds to five years. At the present stage of development of the model we have introduced learning effects only in wind and solar technologies.

7. As in Nordhaus and Boyer (2000) we take into account GHGs emissions other than $\mathrm{CO}_{2}$ by including an exogenous radiative forcing when computing temperature deviations from pre-industrial level. Thus, when we simulate GHGs stabilization policies we consider this additional component and constrain $\mathrm{CO}_{2}$ emissions accordingly to a global target. 
In the description of learning curves the cumulative (installed) world capacity is used as a proxy for the accrual of knowledge that affects the investment cost of a given technology $j$ as follows:

$$
S C_{j}(n, t+1)=B_{j}(n) \Sigma_{n} K_{j}^{*}(n, t)^{-\log _{2} P R_{j}}
$$

where $P R$ is the progress ratio that defines the speed of learning and $K_{j}^{*}$ is the cumulative installed capacity in technology $j$, i.e. power generation capacity gross of depreciation. With every doubling of cumulative capacity the ratio of the new investment cost to its original value is constant and equal to $P R$, until a fixed floor level is reached. By having several electricity production technologies, the model is given the flexibility to change the power production mix and invest in the more appropriate technology for each given climate policy, thus creating the conditions to foster the LbD effects associated with the clean but yet too pricey electricity production techniques.

We also model endogenous technical change through investments in energy R\&D which serve different purposes. First, they increase energy efficiency. Following Popp (2004), technological advances are captured by a stock of knowledge combined with energy in a constant elasticity of substitution (CES) function, thus stimulating energy efficiency improvements:

$$
E S(n, t)=\left[\alpha_{H} H E(n, t)^{\rho}+\alpha_{E N} E N(n, t)^{\rho}\right]^{1 / \rho} .
$$

The stock of knowledge $H E(n, t)$ derives from energy R\&D investments in each region through an innovation possibility frontier characterized by diminishing returns to research, a formulation proposed by Jones (1995) and empirically supported by Popp (2002) for energy-efficient innovations:

$$
H E(n, t+1)=a I_{R \& D}(n, t)^{b} H E(n, t)^{c}+H E(n, t)\left(1-\delta_{R \& D}\right),
$$

$\delta_{R \& D}$ being the depreciation rate of knowledge.

As social returns of $R \& D$ are found to be higher than private one in the case of $R \& D$, the positive externality of knowledge creation is accounted for by assuming that the return on energy R\&D investment is four times higher than the one in physical capital. At the same time, the opportunity cost of crowding out other forms of R\&D is obtained by subtracting four dollars of private investment from the physical capital stock for each dollar of R\&D crowded out by energy R\&D, $\Psi_{R \& D}$, so that the net capital stock for final good production becomes:

$$
K_{C}(n, t+1)=K_{C}(n, t)\left(1-\delta_{C}\right)+\left(I_{C}(n, t)-4 \Psi_{R \& D} I_{R \& D}(n, t)\right)
$$

where $\delta_{C}$ is the depreciation rate of the physical capital stock. We assume new energy crowds out $50 \%$ of other R\&D, as in Popp (2004). This way of 
capturing innovation market failures was also suggested, although in a combined formulation, by Nordhaus (2003).

A second set of energy R\&D investments are devoted to lowering advanced biofuels costs. Conditional on research efforts, their cost may become lower than that of currently used fuels.

The cost of the cellulosic biofuels, $P_{A D V B I O}(n, t)$, is modelled as a decreasing function of investment in dedicated $R \& D$ via a power formulation:

$$
P_{A D V B I O}(n, t)=P_{A D V B I O}(n, 0)\left[T O T_{R \& D, A D V B I O}(n, t)\right]^{-\eta},
$$

where $\eta$ stands for the relationship between new knowledge and cost and

$$
T O T_{R \& D, A D V B I O}(n, t)=\sum_{n} K_{R \& D, A D V B I O}(n, t-2)+\sum_{\tau=t-1} I_{R \& D, A D V B I O}(n, \tau)(13)
$$

represents the world $R \& D$ expenditure for advanced biofuels cumulated up to period $t-2$, to which the two preceding periods $\mathrm{R} \& \mathrm{D}$ investments of country $n$ only are added. We thus assume that the effects of any region-cumulated R\&D influence other regions with a 10 -year ( 2 model periods) delay. The time lag is meant to account for the advantage of first movers in innovation, thus introducing an incentive to $R \& D$ investments that reduces the usual free-riding incentives that derive from the positive externalities produced by R\&D.

\section{CALIBRATION}

This section describes the main features of our model calibration and the main underlying assumptions. For a thorough discussion of model calibration the interested reader is referred to Bosetti, Massetti and Tavoni (2006). To begin with, we choose the values for elasticities of substitution for the CES production functions shown in Figure 2. We have followed the existing modelling literature for the aggregation of the capital-labour bundle with energy (Manne, Mendelsohn and van der Mensbrugghe, 1995; Whalley and Wigle, 1990), and the survey of econometric estimates conducted by Burniaux, Nicoletti and Oliveira-Martins (1992) for the Cobb-Douglas aggregation of capital and labour. As for the lower nests, we have chosen figures that are in line with the empirical literature on substitutability in energy (see Babiker Maskus and Rutherford, 1997; Dahl, 1993; Ko and Dahl, 2001; Lee Oliveira-Martins and van der Mensbrugghe, 1994; Soderholm, 1998).

To calibrate the remaining parameters (factor shares and productivities) of the CES functions, we have computed the first order conditions with respect to all the choice variables and equated all the marginal products to their prices. This is crucially important to avoid "jumps" in the first optimization steps. Euler equations allowed us to calculate the prices of intermediate nests. This yields a system of 40 non linear simultaneous equations that are solved with GAMS/ CONOPT. Prices and quantities for each factor of production are taken from 
various data sources (ENERDATA, 2004, 2005; IEA 2004a; NEA/IEA, 1998, 2005; World Bank, 2004). The base year of calibration is 2002.

For the technology specification currently represented in the model we have assumed that learning occurs in wind and solar electricity production at a progress ratio of 0.87 - i.e. there is a $13 \%$ investment cost decrease for each doubling of world installed capacity. As for the learning parameter for advanced biofuels, we have set it to 0.1 yielding a learning factor of $7 \%$.

Population is exogenous and follows the Common POLES IMAGE (CPI) baseline (van Vuuren, Eickhout, Lucas and den Elzen, 2005). The climate module is adapted from Nordhaus and Boyer (2000). Figures have been adjusted for the different time step length and initial base year. The inter-temporal discount rate is from Nordhaus and Boyer (2000), set equal to 3\% in the base year, and then declining at a constant $0.25 \%$ rate per year. Total factor productivity is assumed to exogenously grow over time to reflect technological progress and all the other structural changes that are difficult to represent in a simplified Ramsey-type growth framework, especially in the case of developing countries. The exponential trend is calibrated to fit the output projection underlying the Common POLES IMAGE (CPI) baseline (van Vuuren, Eickhout, Lucas and den Elzen, 2005).

Finally, the extraction cost functions for each fuel - coal, oil, natural gas and uranium - are calibrated based on resource availability surveys (IEA, 2004a; MIT, 2003; USGS, 2000) and expert judgment.

\section{WITCH BASELINE SCENARIO}

In this Section we present the results of the Baseline scenario, which is the non-cooperative solution without any external GHGs mitigation policy. The algorithm returns the optimal values of the control variables over time and accounts for the free-riding behaviour of each region. The control variables are the investments in all energy technologies, in physical capital and in R\&D, together with the direct uses of fossil fuels. All prices are expressed in 1995USD.

We start by describing the macroeconomic features of our Baseline scenario. Figure 3 shows the dynamics of GDP in two macro-region aggregates. World output is 34 trillions in 2002 and grows steadily to 240 trillions in 2100, a seven fold increase. This is similar to the IPCC-SRES B2 scenario. NON-OECD countries will overcome OECD in terms of output after mid-century and take the lead afterwards, pushed by the continued rise in population. Annual growth rates per region are shown in Figure 4: developing countries experience higher growth rates, but all regions mildly converge by the end of the century.

Figure 5 shows the reductions in energy and carbon intensity throughout the century. Again for the sake of simplicity we show the results for two macroregion aggregates only. The (primary) energy intensity of output decreases considerably throughout the century (see the horizontal axis): investors take into account the increasing cost of energy sources and therefore reduce the amount of energy per unit of output over time. This is also consistent with the historical 
Figure 3. GDP Level per Macro-Region

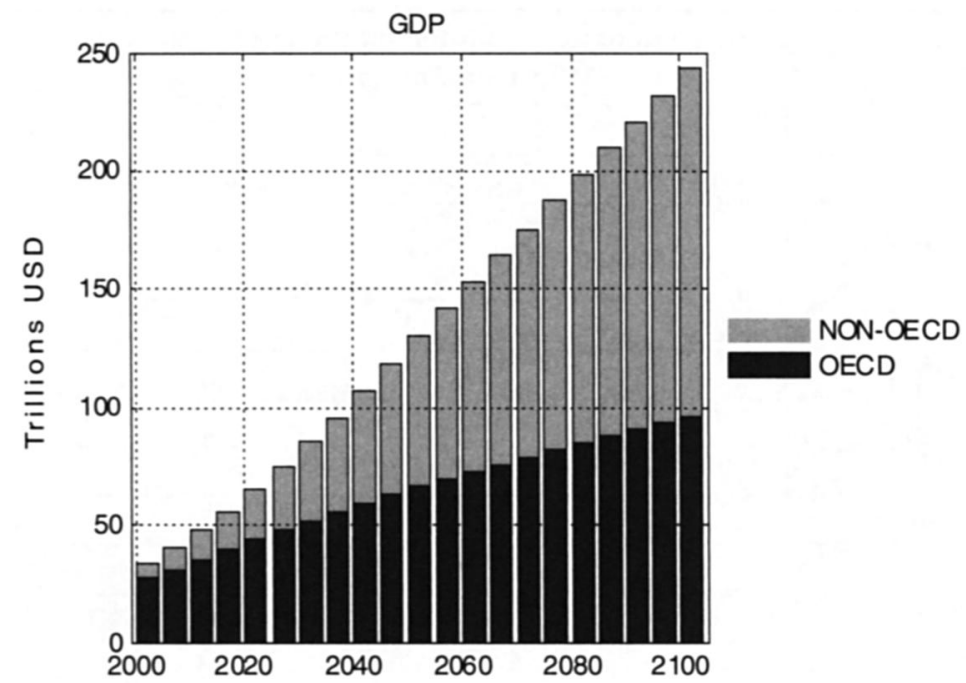

Figure 4. Output Growth by Region

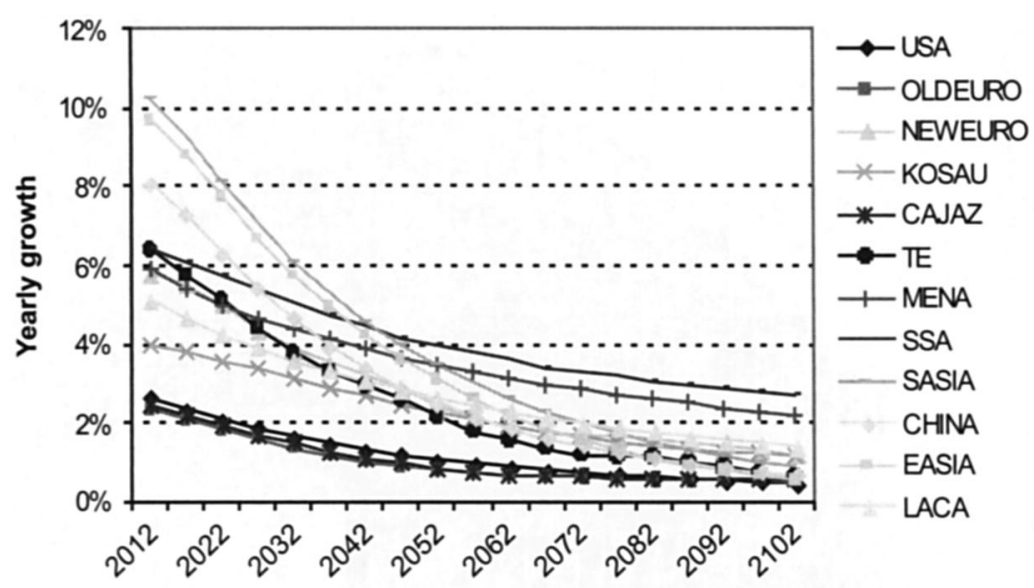

evolution of energy intensity that, for example, halved in the US in the past 50 years. The graph also tells us that the reductions in energy intensity are expected to be stronger in NON-OECD countries: these regions are more energy intensive now, but have large margins of improvement in energy efficiency, and indeed converge to the world average as their economies evolve over time. This yields some positive environmental side effects also without accounting for any $\mathrm{CO}_{2}$ reduction policy as in the Baseline. 
Figure 5. Energy Intensity and Carbon Intensity of Energy Variations w.r.t. 2002

Energy intensity vs carbon intensity of energy w.r.t. first period

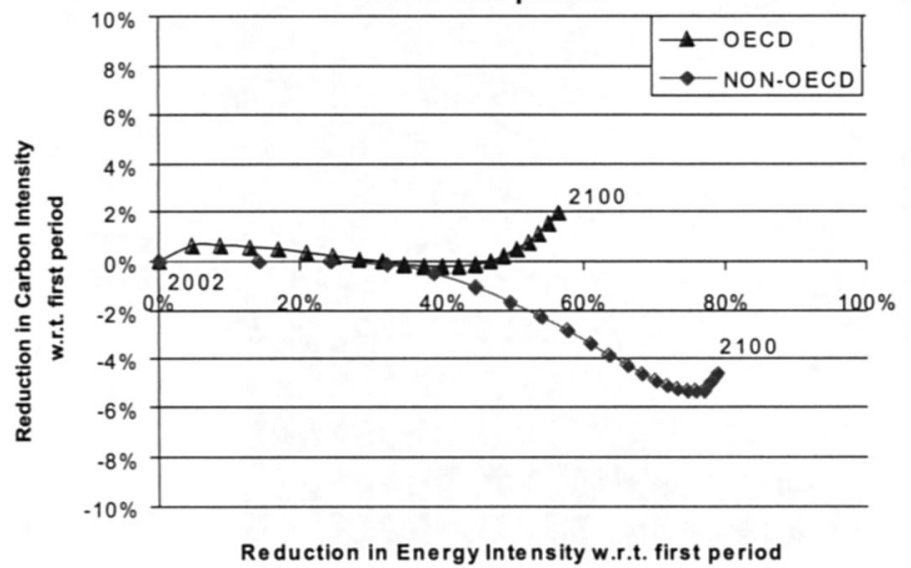

Figure 6. World Primary Energy Demand by Fuel

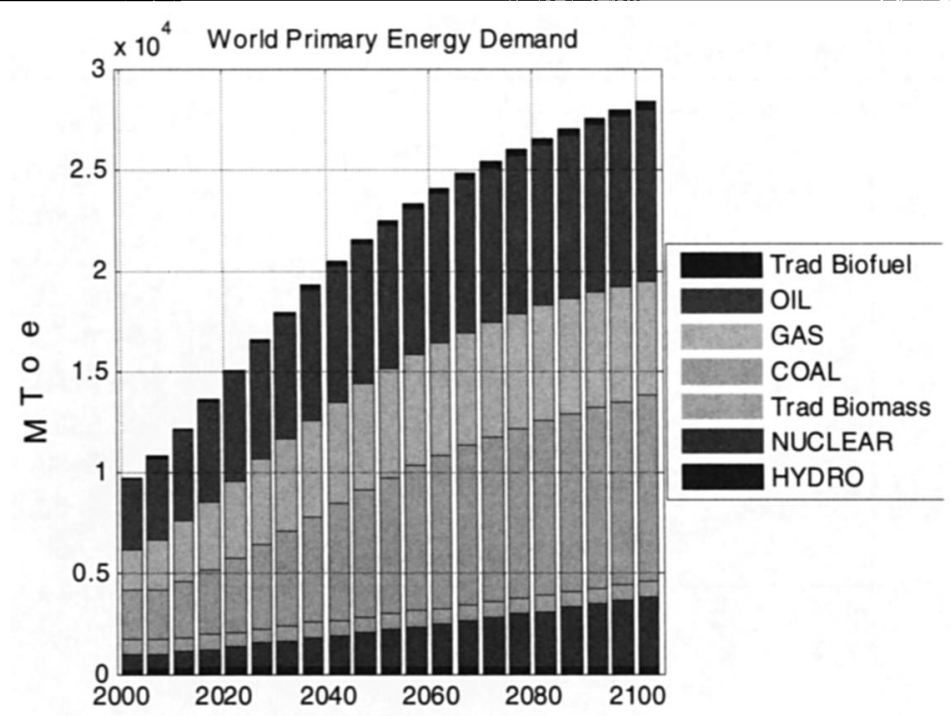

If we look instead at the evolution of carbon intensity of primary energy (see the vertical axis), we note small improvements only in OECD countries and actually a worsening - though very limited - in NON-OECD ones. This implies a continued carbon based evolution of the energy mix, especially in the developing countries. As a term of comparison, the carbon intensity of primary energy in the U.S. has remained somewhat stable in the second half of the century (see Nakicenovic, 1997). 
By looking at the evolution of the world primary energy demand portrayed in Figure 6, we predict a continued use of fossil fuels throughout the century. Oil, coal and natural gas are expected to satisfy the growing need for energy, especially in the form of electricity, by maintaining their shares almost constant. Such a projection clearly depends on the underlying assumption on fuel resource availability and prices. We project a four-fold real increase in oil prices over the century, three-fold for natural gas and coal. However, given the low base year price, oil reaches 85 1995USD/Barrel by the end of the century. This figure might seem too optimistic given current prices in the market, but it is in line with the estimates that account for the large non-conventional oil resources (tar sands, shale oil, coal liquefaction etc.: see IEA, 2005b). Therefore, our Baseline assumes - in line with other projections such as Lackner and Sachs (2005) - that the energy resource base will be sufficient to provide energy demand of a fastgrowing world economy in the next century.

The world power generation mix is shown in Figure 7: fossil-based power generation is expected to continue through the century. Coal reinforces its leading role, especially in the developing countries, which is one of the reasons for the aforementioned dynamics of carbon intensity of energy. The rise in oil and gas prices keeps the nuclear option alive: the share of nuclear energy remains fairly constant. New low-carbon technologies do not become competitive to gain substantial market shares. Wind and solar electricity increases very marginally, and there is no generation of electricity by means of IGCC Coal power plants with Carbon Capture and Sequestration.

As for technical change, energy efficiency improving R\&D investments increase four-fold during the century, passing from 9 1995USD Billions to almost 40. This non-negligible amount is not enough however to increase the share of

\section{Figure 7. World Electricity Mix}

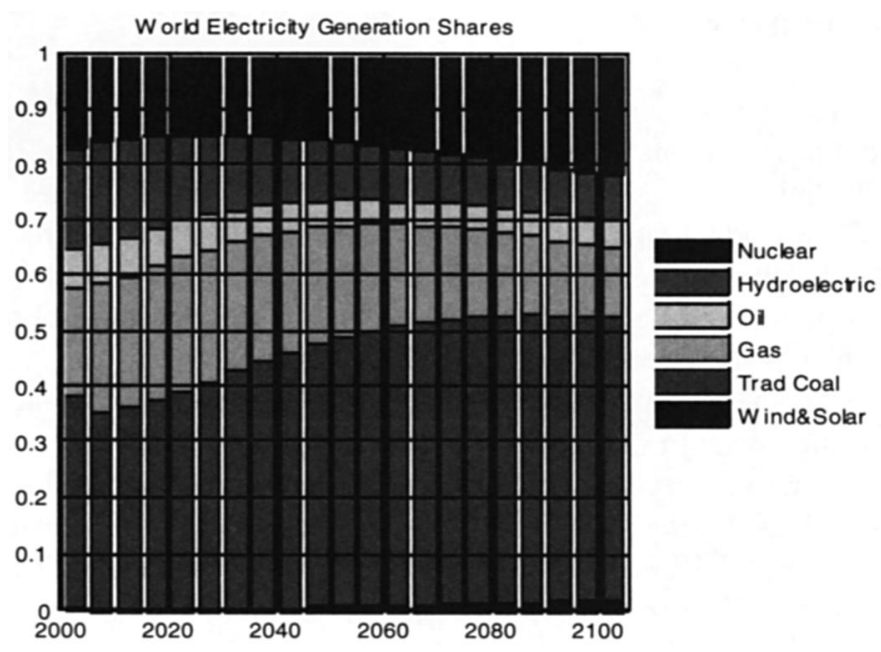




\section{0 / The Energy Journal}

energy R\&D over GDP. As for Learning-by-Doing, the presence of international learning spillovers reduces the incentives of early investments in wind and solar technologies: this is shown in Figure 8, where we show the differences in investments in this technology when the international spillover feature is removed. The incentives to free-ride on carbon free investments delay the adoption of climate friendly technologies in the early periods of the game. Thereafter, the learning by doing effect induces significant investment cost decreases and a faster penetration of the technology.

There are several factors that support this carbon-intensive baseline. First, the absence of any climate policy keeps the carbon prices down to very low values, and prevents the deployment of carbon-free technologies. The negative feedbacks from the climate module are not strong enough to induce significant emissions cuts, mainly because costs and benefits of emissions reductions have different timings: regions have to bear costs for adopting more virtuous technologies first, and they will benefit from lower temperatures only later. Hence, discounting puts more weight on the costs than on the benefits. Second, and more importantly, the regions free-riding behaviour we account for in our non-cooperative solution - on $\mathrm{CO}_{2}$, fuel prices, technology spillovers etc. - does not provide enough incentive to moderate pollution considerably, since any effort is dampened by a non-cooperative behaviour of the other players. This is clear from Figure 9, in which the world industrial $\mathrm{CO}_{2}$ emissions are reported. The non cooperative solution foresees a growth in emissions to $20 \mathrm{GtC}$ in 2100 , a result that falls in the IPCC-SRES B2 range of scenarios. However, in the same figure we also show the emission profile assuming a cooperative behaviour among world regions, i.e. assuming a social planner that maximizes world welfare. In this case emissions would be reduced to almost half the level of the non-cooperative case. This result quantifies the magnitude of the various externalities we account for in our model and stresses the importance of promoting cooperation among countries.

\section{CONCLUSIONS}

This paper has presented the main characteristics and properties of a new model designed for climate policy analysis. The model, called WITCH (World Induced Technical Change Hybrid), is a top-down macro model where different regions of the world strategically interact in determining their optimal energy investments. Optimal investments are the outcome of a dynamic open-loop Nash game with perfect foresight. Investments depend on the dynamics of technical change, which is itself endogenous and depends on investment paths as well as on prices and other economic and climatic variables (including climate policy). Investment decisions in one country depend on those in the other countries, given the several interdependency channels specified in the model. The model is carefully calibrated using the information available in the empirical literature.

This paper has also briefly described the properties of the Baseline scenario produced by WITCH. In our Baseline scenario, free-riding incentives characterize 


\section{Figure 8. Spillover Effects in Learning-by-Doing}

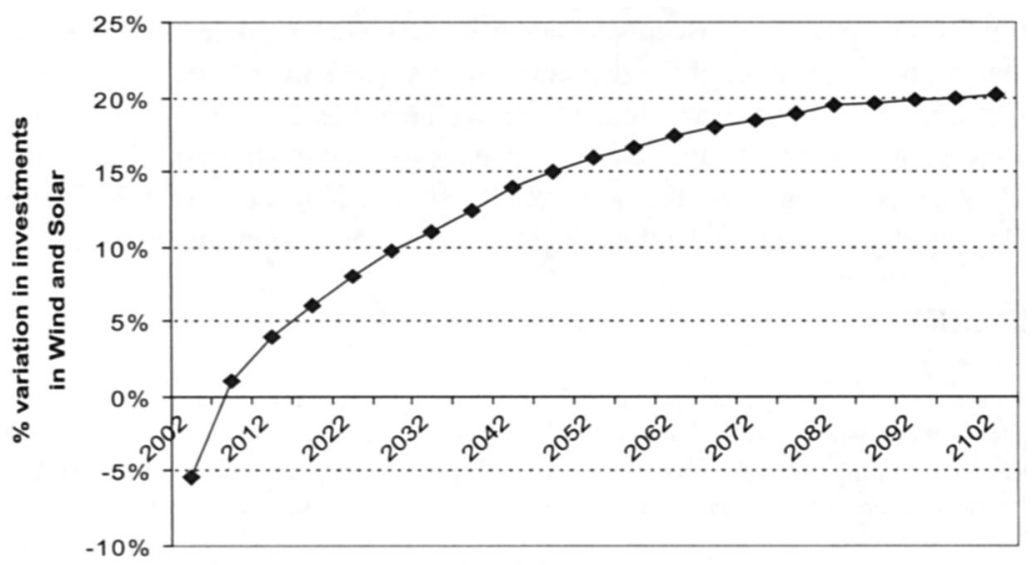

Figure 9. Fossil Fuel Combustion Carbon Emissions

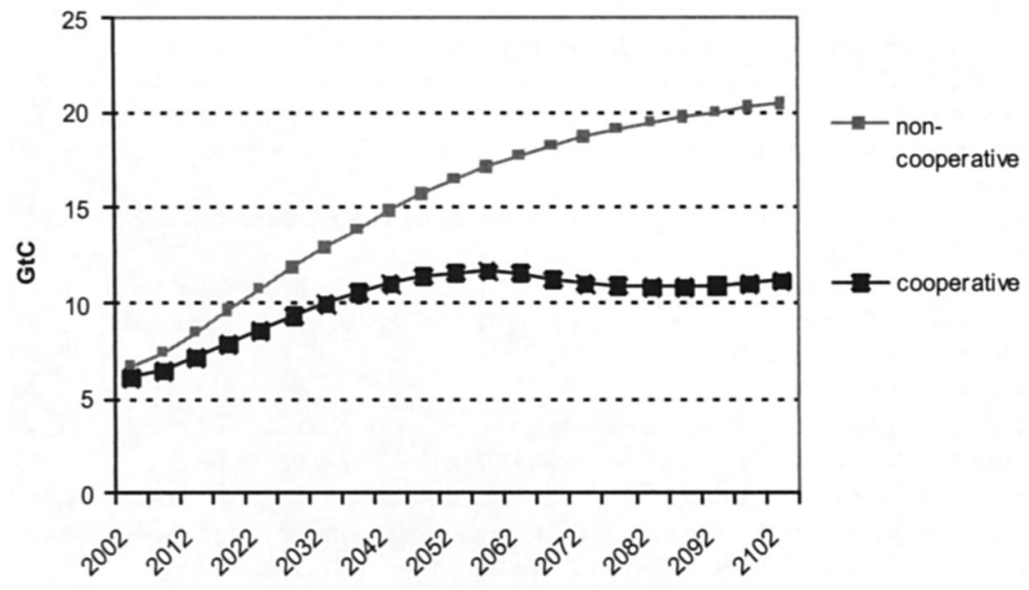

the development and adoption of new climate-friendly technologies. For example, even though the model explicitly allows for the possible use of carbon sequestration, in the absence of any climate policy, all investors in all world regions do not find it convenient to adopt them. For the same reasons, climate friendly R\&D investments are also limited. As a consequence, the fuel-mix remains fairly stable over the time, which produces a fairly conservative Baseline. By comparing the results of the noncooperative and cooperative solutions, we managed to quantify the relevance of the free-riding incentives to prevent the stabilization of the GHGs and avoid potential damages from global warming. It is thus crucial to analyze what would be the impacts of different climate policies (e.g. stabilization targets or emission trading) 


\section{2 / The Energy Journal}

in WITCH. Given the many channels of transmission of climate policy into the economic system (from forward looking investments to Learning-by-Doing, from energy R\&D expenditure to technological spillovers, etc.), climate policy is likely to have an important impact of the dynamics on WITCH's main economic variables. Under what conditions can climate policy achieve the goal of stabilizing GHG concentrations? What are the features of an optimal climate policy? How much would it be technology-based? These are all issues and questions that WITCH can easily address and that will be the subject of future applications of the model.

\section{REFERENCES}

Babiker, M.H., K.E. Maskus, and T.F. Rutherford (1997). "Carbon Taxes and the Global Trading System.” Working Paper 97-7, University of Colorado, Boulder.

Bauer, N., O. Edenhofer and S. Kypreos (2005). "Linking Energy System and Macroeconomic Growth Models. Is the Supply Curve Enough?" Submitted to the Journal of Computational Management Science.

Bosetti, V., E. Massetti and M. Tavoni (2006). "WITCH: Energy Patterns, Technology Options and $\mathrm{CO}_{2}$ Emissions". Fondazione Eni Enrico Mattei, mimeo.

Burniaux, J.M., G. Nicoletti and J. Oliveira-Martins (1992). "GREEN: A Global Model for Quantifying the Costs of Policies to Curb $\mathrm{CO}_{2}$ Emissions." OECD Economic Studies 19, Winter: 49-92.

Clarke, L.E. and J.P. Weyant (2002). "Modeling Induced Technical Change: an Overview." In A. Grubler, N. Nakicenovic and W.D. Nordhaus, eds., Technological Change and the Environment. Resources for the Future, Washington D.C.

Collett, T. (2001). "Natural Gas Hydrates - Vast Resources, Uncertain Future." USGS Fact Sheet 021-01.

Dahl, C. (1993). "A Survey of Energy Demand Elasticities in Support of the Development of the NEMS." United States Department of Energy, October, mimeo.

Edenhofer, O., N. Bauer and E. Kriegler (2005). "The Impact of Technological Change on Climate Protection and Welfare: Insights from the Model MIND." Ecological Economics 54(2): 277-292.

ENERDATA (2004). Energy Statistics.

ENERDATA (2005). Energy Statistics.

Gerlagh R. and B.C.C. van der Zwaan (2004). "A Sensitivity Analysis on Timing and Costs of Greenhouse Gas Abatement, Calculations with DEMETER." Climatic Change 65(1-2): 39-71.

Hansen, L., D. Epple and W. Roberds (1985). "Linear Quadratic Duopoly Models of Resource Depletion." In: T.J. Sargent, ed. . Energy, Foresight, and Strategy. Resources for the Future, Washington D.C.

IEA (2000). Experience Curves for Energy Technology Policy. OECD/IEA, Paris.

IEA (2004a). World Energy Outlook 2004. OECD/IEA, Paris.

IEA (2004b). Biofuels for Transport - An International Perspective. OECD/IEA, Paris.

IEA (2005a). Energy Prices and Taxes - Quarterly Statistics - Fourth Quarter 2005. OECD/IEA, Paris.

IEA (2005b). Resources to Reserves - Oil \& Gas Technologies for the Energy Markets of the Future. OECD/IEA, Paris.

Jones, C. (1995). "R\&D Based Models of Economic Growth.” The Journal of Political Economy 103(4): 759-784.

Ko, J. and C. Dahl (2001). "Interfuel Substitution in US Electricity Generation." Applied Economics 33(14): 1833-1843.

Lackner K. and J. Sachs (2005). “A Robust Strategy for Sustainable Energy.” Brookings Papers on Economic Activity 2:2005.

Lee, H., J. Oliveira-Martins and D. van der Mensbrugghe (1994). "The OECD GREEN Model: an Updated Overview.” OCED Development Centre, Working Paper 97, OECD, Paris. 
Manne, A., R. Mendelsohn and R. Richels (1995). "MERGE: a Model for Evaluating Regional and Global Effects of GHG Reduction Policies." Energy Policy 23(1): 17-34.

MIT (2003). The Future of Nuclear Power - An Interdisciplinary MIT Study. Massachusetts Institute of Technology, Boston.

Nakicenovic, N. (1997). "Technological Change and Diffusion as a Learning Process." Perspectives in Energy 4(2): 173-189.

NEA/IEA (1998). Projected Costs of Generating Electricity: 1998 Update. OECD, Paris.

NEA/IEA (2005). Projected Costs of Generating Electricity: 2005 Update. OECD, Paris.

Nordhaus, W.D. (2003). "Modeling Induced Innovation in Climate Change Policy.” In A. Grubler, N. Nakicenovic and W.D. Nordhaus, eds., Technological Change and the Environment. Resources for the Future, Washington D.C.

Nordhaus, W.D. and J. Boyer (2000). Warming the World. Cambridge: MIT Press.

Popp, D. (2002). "Induced Innovation and Energy Prices." The American Economic Review 92(1): 160-180.

Popp, D. (2004). "ENTICE: Endogenous Technological Change in the DICE Model of Global Warming." Journal of Environmental Economics and Management, 48(1): 742-768.

Soderholm, P. (1998). "The Modeling of Fuel Use in the Power Sector: a Survey of Econometric Analyses." The Journal of Energy Literature 4(2): 3-27.

Thompson, P. and T.G. Taylor (1995). "The Capital-Energy Substitutability Debate: a New Look." Review of Economics and Statistics 77(3): 565-569.

U.S. Geological Survey, World Assessment Team (2000). World Petroleum Assessment.

van Vuuren, D.P., B. Eickhout, P.L. Lucas and M.G.J. den Elzen (2005). "Long-Term Multi-GasScenarios to Stabilize Radiative Forcing - Exploring Costs and Benefits Within an Integrated Assessment Framework." The Energy Journal, Forthcoming.

Whalley, J. and R. Wigley (1990). "The International Incidence of Carbon Taxes." Paper presented at the Conference on "Economic Policy Responses to Global Warming", Rome, 4-6 October.

World Bank (2004). “World Development Indicators 2004.” The World Bank, Washington D.C.

\section{APPENDIX: MODEL EQUATIONS AND LIST OF VARIABLES}

In this Appendix we reproduce the main equations of the model. The list of variables is reported at the end. In each region, indexed by $n$, a social planner maximizes the following utility function:

$$
W(n)=\sum_{t} U[C(n, t), L(n, t)] R(t)=\Sigma_{t} L(n, t)\{\log [c(n, t)]\} R(t),
$$

where $t$ are 5-year time spans and the pure time preference discount factor is given by:

$$
R(t)=\prod_{v=0}^{t}[1+\rho(v)]^{-5},
$$

where the pure rate of time preference $\rho(v)$ is assumed to decline over time.

Moreover, $c(n, t)=\frac{C(n, t)}{L(n, t)}$ is per capita consumption. 


\section{4 / The Energy Journal}

\section{Economic module}

The budget constraint defines consumption as net output less investments:

$$
\begin{aligned}
C(n, t)= & Y(n, t)-I_{C}(n, t)-\Sigma_{j} I_{R \& D, j}(n, t)-\sum_{j} I_{j}(n, t)-\Sigma_{j} O \& M_{j}(n, t) \\
& -\Sigma_{f}\left(P_{f}(n, t) X_{f, \text { extr }}(n, t)+P_{f}^{\text {int }}(t) X_{f, \text { netimp }}(n, t)\right) \\
& -P_{C C S}(n, t) C C S(n, t)
\end{aligned}
$$

Output is produced via a nested CES function that combines a capital-labour aggregate and energy; capital and labour are obtained from a Cobb-Douglas function. The climate damage $\Omega$ reduces gross output: to obtain net output we subtract the costs of the natural resources and CCS ( $j$ indexes technologies):

$$
Y(n, t)=\frac{\operatorname{TFP}(n, t)\left[a(n)\left(K_{C}^{1-\beta(n)}(n, t) L^{\beta(n)}(n, t)\right)^{\rho}+(1-a(n)) E S(n, t)^{\rho}\right]^{1 / \rho}}{\Omega(n, t)}
$$

Total factor productivity $\operatorname{TFP}(n, t)$ evolves exogenously with time. Final good capital accumulates following the standard perpetual rule, but four dollars of private investments are subtracted from it for each dollar of R\&D crowded out by energy R\&D:

$$
K_{C}(n, t+1)=K_{C}(n, t)\left(1-\delta_{C}\right)+\left(I_{C}(n, t)-4 \Psi_{R \& D} I_{R \& D}(n, t)\right) .
$$

Labour is assumed to be equal to population and evolves exogenously. Energy services are an aggregate of energy and a stock of knowledge combined with a CES function:

$$
E S(n, t)=\left[\alpha_{H} H E(n, t)^{\rho_{E S}}+\alpha_{E N} E N(n, t) \rho_{E S}\right]^{1 / \rho_{E S}}
$$

The stock of knowledge $H E(n, t)$ derives from energy R\&D investment:

$$
H E(n, t+1)=a I_{R \& D}(n, t)^{b} H E(n, t)^{c}+H E(n, t)\left(1-\delta_{R \& D}\right) .
$$

Energy is a combination of electric and non-electric energy:

$$
E N(n, t)=\left[\alpha_{E L} E L(n, t)^{\rho_{E N}}+\alpha_{N E L} N E L(n, t)^{\rho_{E N}}\right]^{1 / \rho_{E N}}
$$

Each factor is further decomposed into several sub-components. Figure 2 portrays a graphical illustration of the energy sector. Factors are aggregated using CES, linear and Leontief production functions.

For illustrative purposes, we show how electricity is produced via capital, operation and maintenance and resource use through a zero-elasticity Leontief aggregate:

$$
E L_{j}(n, t)=\min \left\{\mu_{n, j} K_{j}(n, t) ; \tau_{n, j} O \& M_{j}(n, t) ; \zeta_{n, j} X_{j, E L}(n, t)\right\}
$$


Capital for electricity production technology accumulates in the usual way:

$$
K_{j}(n, t+1)=K_{j}(n, t)\left(1-\delta_{j}\right)+\frac{I_{j}(n, t)}{S C_{j}(n, t)},
$$

where the new capital investment $\operatorname{cost} S C(n, t)$ decreases with the world cumulated installed capacity by means of Learning-by-Doing:

$$
S C_{j}(n, t)=B_{j}(n)\left[\Sigma_{n} K_{j}^{*}(n, t)\right]^{-\log _{2} P R_{j}} .
$$

Operation and maintenance is treated like an investment that fully depreciates every year. The resources employed in electricity production are subtracted from output in equation (A4). Their prices are calculated endogenously using a reduced-form cost function that allows for non-linearity in both the depletion effect and in the rate of extraction:

$$
P_{f}(n, t)=\chi_{f}(n)+\pi_{f}(n)\left[Q_{f}(n, t-1) / \bar{Q}_{f}(n, t)\right]^{\psi_{f}(n)}
$$

where $Q_{f}$ is cumulative extraction of fuel $f$ :

$$
Q_{f}(n, t-1)=Q_{f}(n, 0)+\Sigma_{s=0}^{t-1} X_{f, e x t r}(n, s) .
$$

Each country covers consumption of fuel $f, X_{f}(n, t)$, by either domestic extraction or imports, $X_{f, \text { netimp }}(n, t)$, or by a combination of both. If the country is a net exporter, $X_{f, \text { netimp }}(n, t)$ is negative.

$$
X_{f}(n, t)=X_{f, e x t r}(n, t)+X_{f, n e t i m p}(n, t)
$$

\section{Climate Module}

GHGs emissions from combustion of fossil fuels are derived by applying stoichiometric coefficients to the total amount of fossil fuels utilized minus the amount of $\mathrm{CO}_{2}$ sequestered:

$$
\mathrm{CO}_{2}(n, t)=\Sigma_{f} \omega_{f, \mathrm{CO}_{2}} X_{f}(n, t)-C C S(n, t) .
$$

The damage function impacting output varies with global temperature:

$$
\Omega(n, t)=\frac{1}{1+\left(\theta_{1, n} T(t)+\theta_{2, n} T(t)^{2}\right)} .
$$

Temperature increases through augmented radiating forcing $F(t)$ :

$$
T(t+1)=T(t)+\sigma_{1}\left\{F(t+1)-\lambda T(t)-\sigma_{2}\left[T(t)-T_{L o}(t)\right]\right\}
$$


which in turn depends on $\mathrm{CO}_{2}$ concentrations:

$$
F(t)=\eta\left\{\log \left[M_{A T}(t) / M_{A T}^{P I}\right]-\log (2)\right\}+O(t),
$$

caused by emissions from fuel combustion and land use change:

$$
\begin{aligned}
& M_{A T}(t+1)=\sum_{n}\left[C O_{2}(n, t)+L U_{j}(t)\right]+\phi_{11} M_{A T}(t)+\phi_{21} M_{U P}(t) \\
& M_{U P}(t+1)=\phi_{22} M_{U P}(t)+\phi_{12} M_{A T}(t)+\phi_{32} M_{L O}(t) \\
& M_{L O}(t+1)=\phi_{33} M_{L O}(t)+\phi_{23} M_{U P}(t) .
\end{aligned}
$$

Model variables are denoted with the following symbols:

$W=$ welfare

$U=$ instantaneous utility

$C=$ consumption

$c=$ per-capita consumption

$L=$ population

$R=$ discount factor

$Y=$ production

$I_{c}=$ investment in final good

$\mathrm{I}_{R \& D}=$ investment in energy $\mathrm{R} \& \mathrm{D}$

$\mathrm{I}_{\mathrm{j}}=$ investment in technology $\mathrm{j}$

$O \& M=$ investment in operation and maintenance

$T F P=$ total factor productivity

$\mathrm{K}_{c}=$ final good stock of capital

$E S=$ energy services

$\Omega=$ damage

$P_{j}=$ fossil fuel prices

$X_{j}=$ fuel resources

$P_{C C S}=$ price of CCS

$C C S=\mathrm{CO}_{2}$ sequestered

$H E=$ energy knowledge

$E N=$ energy

$E L=$ electric energy

$N E L=$ non-electric energy

$\mathrm{K}_{j}=$ stock of capital of technology $\mathbf{j}$

$S C_{j}=$ investment cost

$\mathrm{CO}_{2}=$ emissions from combustion of fossil fuels

$M_{A T}=$ atmospheric $\mathrm{CO}_{2}$ concentrations 
$L U=$ land-use carbon emissions

$M_{U P}=$ upper oceans/biosphere $\mathrm{CO}_{2}$ concentrations

$M_{L O}=$ lower oceans $\mathrm{CO}_{2}$ concentrations

$F=$ radiative forcing

$T=$ temperature level 